Technological University Dublin

DƯBLIN

ARROW@TU Dublin

2010-10-01

\title{
Determination of Threshold Exposure and Intensity for Recording Holograms in Thick Green-Sensitive Acrylamide-Based Photopolymer
}

\author{
Mohammad Sultan Mahmud \\ Moroccan Association of Science, Innovation and Research \\ Izabela Naydenova \\ Technological University of Dublin, izabela.naydenova@tudublin.ie \\ Tzwetanka Bebeva \\ Technological University of Dublin
}

See next page for additional authors

Follow this and additional works at: https://arrow.tudublin.ie/cieoart

Part of the Chemistry Commons

\section{Recommended Citation}

Mahmud, M. et al. (2010) Determination of threshold exposure and intensity for recording holograms in thick green-sensitive acrylamide-based photopolymer. Appl. Opt. vol.49, pp. 5276-5283. http://www.opticsinfobase.org/ao/abstract.cfm?URI=ao-49-28-5276. doi:10.1364/A0.49.005276

This Article is brought to you for free and open access by the Centre for Industrial and Engineering Optics at ARROW@TU Dublin. It has been accepted for inclusion in Articles by an authorized administrator of ARROW@TU

Dublin. For more information, please contact

arrow.admin@tudublin.ie, aisling.coyne@tudublin.ie, gerard.connolly@tudublin.ie.

Funder: Technological University of Dublin

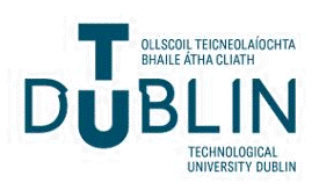




\section{Authors}

Mohammad Sultan Mahmud, Izabela Naydenova, Tzwetanka Bebeva, Raghavendra Jallapuram, Suzanne Martin, and Vincent Toal 


\title{
Determination of threshold exposure and intensity for recording holograms in thick green-sensitive acrylamide-based photopolymer
}

\author{
Mohammad Sultan Mahmud, ${ }^{1,2,3, \star}$ Izabela Naydenova, ${ }^{2,3}$ Tzwetanka Babeva, ${ }^{2,4}$ \\ Raghavendra Jallapuram, ${ }^{2,3}$ Suzanne Martin, ${ }^{2}$ and Vincent Toal ${ }^{2,3,5}$ \\ 'Institute of Nanomaterials and Nanotechnology, Moroccan Association of Science, Innovation and Research, \\ École normale supérieure de l'Enseignement technique, Madinat El Irfane 10100, Rabat, Morocco \\ ${ }^{2}$ Centre for Industrial and Engineering Optics, Dublin Institute of Technology, Dublin 8, Ireland \\ ${ }^{3}$ School of Physics, Faculty of Science, Dublin Institute of Technology, Dublin 8, Ireland \\ ${ }^{4}$ Central Laboratory of Photo processes, Bulgarian Academy of Sciences, 1113 Sofia, Bulgaria \\ ${ }^{5}$ e-mail: vincent.toal@dit.ie. \\ ${ }^{*}$ Corresponding author: mohammad.mahmud@dit.ie
}

Received 28 April 2010; revised 11 August 2010; accepted 19 August 2010;

posted 24 August 2010 (Doc. ID 127587); published 23 September 2010

\begin{abstract}
For optical data storage applications, it is essential to determine the lowest intensity (also known as threshold intensity) below or at which no data page or grating can be recorded in the photosensitive material, as this in turn determines the data capacity of the material. Here, experiments were carried out to determine the threshold intensity below which the formation of a simple hologram-a holographic diffraction grating in a green-sensitized acrylamide-based photopolymer-is not possible. Two main parameters of the recording layers-dye concentration and thickness-were varied to study the influence of the density of the generated free radicals on the holographic properties of these layers. It was observed that a minimum concentration per unit volume of free radicals is required for efficient cross-linking of the created polymer chains and for recording a hologram. The threshold intensity below which no hologram can be recorded in the Erythrosin B sensitized layers with absorbance less than 0.16 was $50 \mu \mathrm{W} / \mathrm{cm}^{2}$. The real-time diffraction efficiency was analyzed in the early stage of recording. It was determined that the minimum intensity required to obtain diffraction efficiency of $1 \%$ was $90 \mu \mathrm{W} / \mathrm{cm}^{2}$, and the minimum required exposure was $8 \mathrm{~mJ} / \mathrm{cm}^{2}$. It was also determined that there is an optimum dye concentration of $1.5 \times 10^{-7} \mathrm{~mol} / \mathrm{L}$ for effective recording above which no increase in the sensitivity of the layers is observed. (C) 2010 Optical Society of America
\end{abstract}

OCIS codes: $\quad 090.2900,050.0050$.

\section{Introduction}

Photopolymers [1-10] are considered one of the most versatile holographic recording media due to their high sensitivity, wide dynamic range, and relatively low cost. Many photopolymers have the advantage that they are self-developing, needing no wet proces-

0003-6935/10/285276-08\$15.00/0

(C) 2010 Optical Society of America sing or thermal treatment. For holographic data storage applications, it is crucial to fabricate thick photopolymer layers in which multiple holograms can be recorded at the same location in the layer. The thickness of the recording layer is particularly important when phase code multiplexing is utilized.

Previous studies [11] of transmission holographic gratings recorded in thick green-sensitive acrylamidebased photopolymer layers $[4,5,11]$ demonstrated that, at higher absorbance $\left(A_{532 \mathrm{~nm}}=0.42\right)$ and above a 
particular layer thickness ( $450 \mu \mathrm{m})$, the overall diffraction efficiency drops significantly because of holographic scattering. The losses due to noise gratings could be minimized if layers of low absorbance were used. One of the aims of this paper is to investigate how reducing of the photopolymer layer's absorption influences the recording properties of layers ranging in thickness from 100 to $350 \mu \mathrm{m}$. Our effort is to characterize the holographic recording in its early stages when very low exposure intensity is used. By using layers with different thicknesses and by varying their dye concentration, we can study the influence of the density of the generated free radicals on the holographic properties of thick photopolymer layers. We have determined the threshold intensity and threshold exposure needed to obtain $1 \%$ diffraction efficiency, a value chosen as appropriate for the holographic data storage applications in which many holograms are to be recorded in the same volume of photopolymer in these layers. In this paper, the quantity defined as "exposure" is actually an "energy density exposure," i.e., the total exposure energy delivered per unit area.

\section{Theory}

Photopolymerization is a chain reaction involving three steps [5,12-16]: initiation, propagation, and termination. Initiation consists of two chemical reaction processes: the production of free radicals under illumination and the binding of a free radical with a monomer $(M)$ to form a monomer radical. During propagation, a monomer radical combines with other monomers to form a large polymer radical $\left(M^{*}\right)$. Termination occurs when the radical attached to the end of the growing polymer chain bonds with another radical. The photopolymerization process can

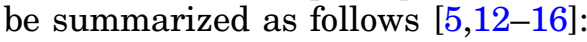

$$
\begin{aligned}
& \text { Initiation : } \quad(i) \quad P I \stackrel{h \nu}{\rightarrow} R^{*}, \quad R_{R}=\frac{d R^{*}}{d t}=2 \cdot \Phi \cdot I_{a}(x) \\
& =2 \cdot \Phi \cdot I(x)[1-\exp (-\varepsilon \cdot c \cdot x)] ; \\
& \text { (ii) } R^{*}+M_{i} \rightarrow M_{i}^{*}, \quad R_{I}=\frac{d M_{i}^{*}}{d t}=k_{i}\left[R^{*}\right] \cdot[M] ; \quad \text { (1b) }
\end{aligned}
$$

$$
\text { Propagation : } \quad M_{i}^{*}+M^{k_{p}} M_{i+1}^{*}, \quad R_{P}=k_{p}\left[M_{i}^{*}\right] \cdot[M] ;
$$

$$
\text { Termination : } \begin{array}{rlr}
M_{i}^{*}+ & M_{i}^{*} \stackrel{k_{t}}{\rightarrow} \text { polymer, } & R_{T}=\frac{d M_{t}^{*}}{d t} \\
=k_{t}\left[M_{i}^{*}\right]^{2}, & (1 \mathrm{~d})
\end{array}
$$

where $P I, R^{*}, M_{i}$, and $M_{i}^{*}$ are the photoinitiator, free radicals, monomer, and the unterminated polymeric chains, respectively. $I(x)$ is the recording intensity, and $I_{a}(x)$ is the intensity absorbed by the sample, which is equivalent to $I(x)\left(1-e^{-A}\right)$. $\Phi$ is the quantum yield, defined as the number of pairs of radicals produced per absorbed photon [17], $\varepsilon$ is the molar absorptivity of the solution, $c$ is the dye concentration, (mol/L), $x$ is the layer thickness, and $A(=\varepsilon . c . x)$ is the absorbance of the photosensitive layer. $k_{r}, k_{i}$, $k_{p}$, and $k_{t}$, are the free radical generation, initiation, propagation, and termination constants, respectively. $R_{R}, R_{I}, R_{P}$, and $R_{T}$ are the free radical generation, monomer radical generation (or initiation), propagation, and termination rate, respectively.

From the above equations, it is seen that the absorbance of the layer governs the rate of initiation. The rate of propagation strongly depends on the reactivity of the monomers and on their concentration. The chemical structure and composition of the monomer affect the values of $k_{p}$ and $k_{t}$ and, therefore, also affect the termination process [18]. The rate at which monomers are polymerized is given as $[17,19,20]$

$$
-\frac{\partial[M]}{\partial t}=R_{I}+R_{P}
$$

where $[M]$ is the monomer concentration, and $R_{I}$ and $R_{P}$ are the monomer radical generation and polymer chain propagation rate, respectively.

The rate of initiation depends on the recording intensity, concentration of the absorber, molar absorptivity, layer thickness, and the quantum yield of production of radicals. Two parameters, the layer thickness and the concentration of the dye (and thus the layers absorbance), are varied to determine the threshold intensity. It was assumed that the molar absorptivity and the quantum yield remain constant because a single dye sensitizer (Erythrosine B) at relatively low concentrations was used as the sensitizer. No formation of aggregates was observed. This was confirmed by the fact that the absorption spectrum shape and peak position remained unchanged for all dye concentrations. The grating recording process can be described as follows: production of polymer in bright interference fringe areas is accompanied by concentration-gradient-driven diffusion of the monomer from the dark areas, leading to a density increase in the bright regions and an accompanying refractive-index modulation, which maps the light intensity distribution. Thus, a grating can be obtained.

The holographic gratings studied in this paper were recorded in relatively thick photopolymer layers, with thicknesses varying between 100 and $350 \mu \mathrm{m}$, and relatively low absorption $(<0.16)$ to avoid significant losses caused by holographic scattering. Because the absorbance at a particular thickness is related to the dye concentration, the decreased absorbance would mean a smaller number of dye molecules per unit volume. This leads to a lower rate of production of free radicals. There are two main factors that could be influencing the effectiveness of the diffraction grating formation at a low rate of free radical generation. First, the presence of oxygen in the layers can lead to the quenching of the free radicals, and thus they are not available for triggering the free-radical polymerization process. At higher recording intensities, the 
number of the available oxygen molecules is exceeded by the number of the created free radicals, and the polymerization process will take place. The second factor is the balance between the polymerization rate and the rate of cross-linking of the polymer chains and the diffusion processes. It is well known from studies [19-25] that this balance is crucial for the hologram formation in photopolymer layers.

\section{Experiment}

\section{A. Preparation of Thick Photopolymer Layers}

The chemicals used to prepare photopolymer layers are an acrylamide monomer ( $0.6 \mathrm{~g})$, a N, $\mathrm{N}^{\prime}$-methylenebisacrylamide cross-linking monomer $(0.2 \mathrm{~g})$, a triethanolamine initiator $(2 \mathrm{ml}), 10 \mathrm{ml}$ polyvinyl alcohol binder (20 wt. \% /vol. water stock solution), and Erythrosine B sensitizing dye $(0.11$ wt. $\%$ /vol. water based stock solution) $[4,5,11]$. The concentration of the dye was adjusted to maintain constant absorbance, independent of the thickness. The $20 \%$ concentration of PVA was used to enable faster drying of the photopolymer layers and to facilitate the fabrication of thick dry photopolymer layers. After mixing for 30-40 min, the photopolymer solution was deposited in a Petri dish. Once dry, the layer was removed and placed on a glass slide for holographic recording. Layer thicknesses were measured using a white-light surface profilometer (Micro XAM S/N 8038).

\section{B. Experimental Setup}

A two-beam holographic optical setup (Fig. 1) with an angle of $80^{\circ}$ between the beams was used to record unslanted transmission gratings using an argon ion laser $(\lambda=514.5 \mathrm{~nm})$. The gratings were recorded in layers with thicknesses of $100,200,250$, and $350 \mu \mathrm{m}$ at various intensities ranging from 0.08 to $1.0 \mathrm{~mW} / \mathrm{cm}^{2}$ at a spatial frequency of 2500 lines $/ \mathrm{mm}$.

The recording intensity was controlled by a variable neutral density filter $(\mathrm{N})$. The absorption of the photopolymer was negligible at $633 \mathrm{~nm}$ wavelength so a He-Ne laser $(633 \mathrm{~nm})$ was used as a probe beam at the Bragg angle to monitor the diffracted intensity $\left(I_{D}\right)$ during recording. Both the probe and recording beams were vertically polarized. The setup was sufficiently stable for recording gratings at the above spatial frequency and exposure times. An optical interferometer that included an in situ control system $[26,27]$ can be developed for precise and continuous monitoring of the overall stability of the setup. The diffraction efficiency (DE) is defined here as the ratio of the first-order diffracted beam intensity $\left(I_{D}\right)$ and the incident beam intensity $\left(I_{0}\right)$ of the probe beam expressed as a percentage.

\section{Results and Discussion}

\section{A. Real-time DE Measurements}

To investigate the threshold intensity, various low levels of intensities ranging from 0.08 to $1.0 \mathrm{~mW} / \mathrm{cm}^{2}$ were used for recording the gratings. Figure 2 shows the dependence of $\mathrm{DE}$ on exposure time for recording

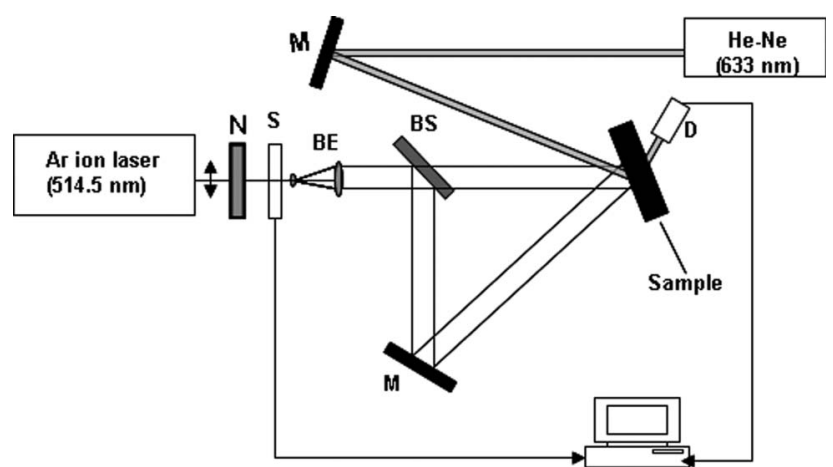

Fig. 1. Experimental setup: N, variable neutral density filter; $\mathrm{S}$, shutter; BE, beam expander; BS, beam splitter; M, mirror; D, optical power meter. $\mathrm{He}-\mathrm{Ne}$ laser $(633 \mathrm{~nm})$ is used for monitoring diffraction efficiency during recording.

in layers with absorbances of $0.025,0.065,0.11$, and 0.16 and thicknesses of $100,200,250$, and $350 \mu \mathrm{m}$ at intensities of 0.08 and $0.7 \mathrm{~mW} / \mathrm{cm}^{2}$. It was found that, at absorbance $A=0.025$ and at the intensity of $80 \mu \mathrm{W} / \mathrm{cm}^{2}$, no DE was measured for any thicknesses, suggesting that the number of the free radicals produced was insufficient to start the recording process. The DE increases both with exposure and absorbance and reaches a maximum for all layer thicknesses. Further increase of exposure leads to an oscillatory behavior of DE, typical for overmodulated volume gratings [28], and none of the gratings reaches $100 \%$ DE mainly due to insufficient absorbance for starting the polymerization process. At lower absorbance $(A=0.025,0.065)$ thin layers show higher $\mathrm{DE}$ than the thick layers but vice versa at higher absorbance $(A=0.11,0.16)$. This is mainly because, at lower absorbances, dye concentrations in thick layers are lower than in the thin layers. At higher absorbance, as the thickness increases, the maximum DE decreases mainly due to the noise grating [11]. For example, a $350 \mu \mathrm{m}$ layer has less DE than a $\overline{250} \mu \mathrm{m}$ layer. Very long exposure $(200 \mathrm{~s})$ is used to obtain a good comparison between various layer thicknesses and absorbances.

Once the number of free radicals produced is sufficient for monomers to be polymerized and for the diffraction grating to grow, then the maximum achievable diffraction efficiency increases with both the absorbance and the intensity. Previous measurements have shown that a careful balance is required between the polymerization and the diffusion rate to obtain the maximum diffraction efficiency [19-25].

\section{B. Intensity and Exposure Requirements for 1\% DE}

Figure 3 shows the times required for $1 \% \mathrm{DE}$ at different absorptions. Each data point in each of these individual graphs was obtained from the DE growth curve for the corresponding layer thickness, intensity, and absorbance. The time required to reach $1 \%$ $\mathrm{DE}$ depends on the number of free radicals formed that is a function of quantum yield and the numbers of dye molecules and photons supplied. Because the quantum yield is constant, the time for $1 \% \mathrm{DE}$ would 

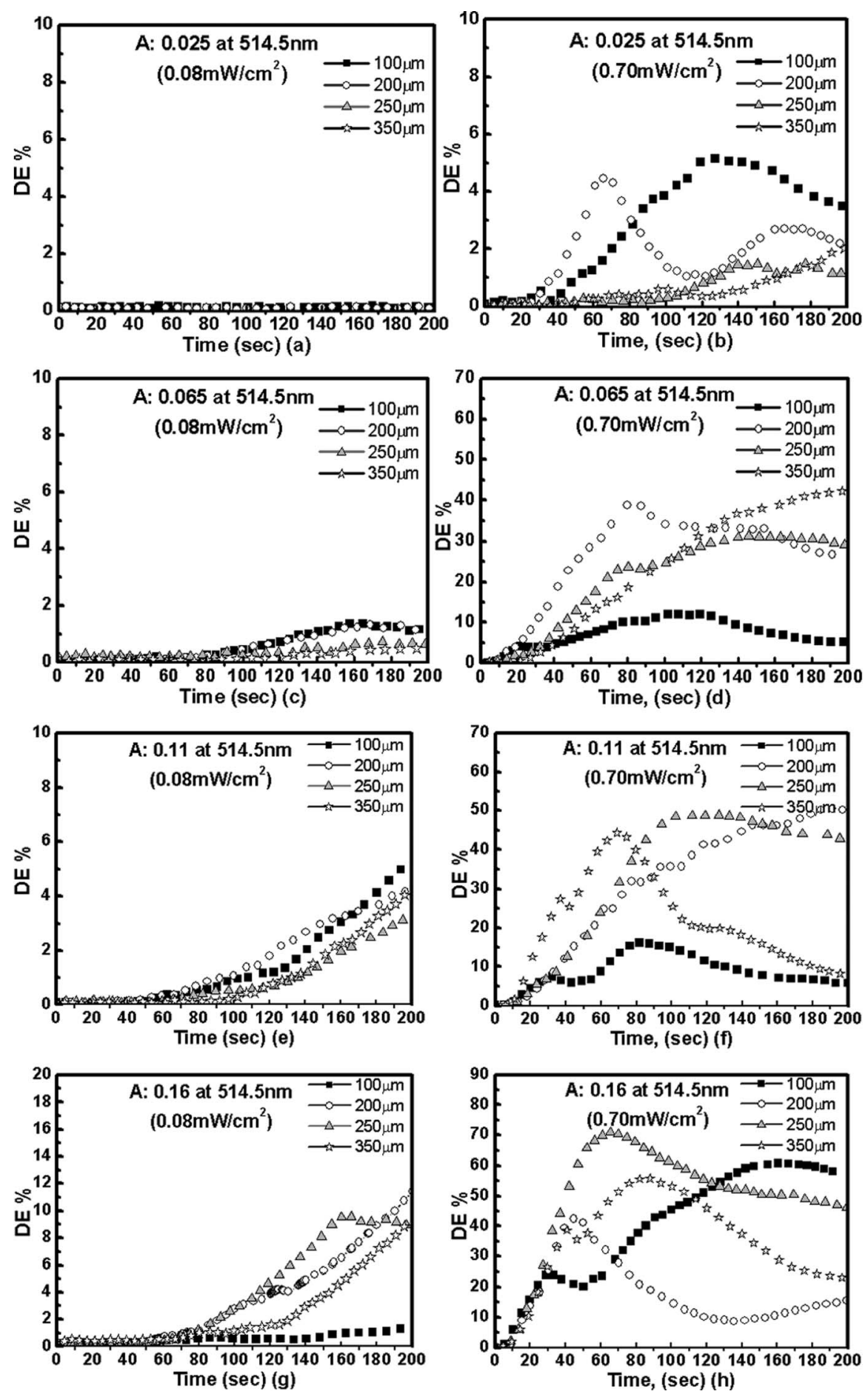

Fig. 2. DE versus exposure time for absorbances (a), (b) 0.025, (c), (d) 0.065, (e), (f) 0.11, and (g), (h) 0.16 for layer thicknesses, (匹) 100, (O) $200,(\Delta) 250$, and (*) $350 \mu \mathrm{m}$ at recording intensities of 0.08 and $0.7 \mathrm{~mW} / \mathrm{cm}^{2}$.

be expected to depend on the intensity (the number of photons supplied) and on the absorbance (the number of dye molecules). Therefore, for constant absorbance, the time should not depend on thickness. This is observed in Fig. 3(d). However, at much lower absorbance [Fig. 3(a)] a marked dependence on thickness is observed despite absorbance being constant. Figures 3(b) and 3(c) show the results for intermediate values of absorbance. The possible reason of thickness dependence of the time required for $1 \%$ $\mathrm{DE}$ at smaller absorbance may be the presence of oxygen molecules in the layers that inhibit the radical-induced polymerization. It can be expected that the thinnest layer have the smallest amount of oxygen (because of the smallest volume of the layer), and this explains the shorter inhibition period as compared to the thickest layer where more oxygen molecules can be found in the volume and longer time is 

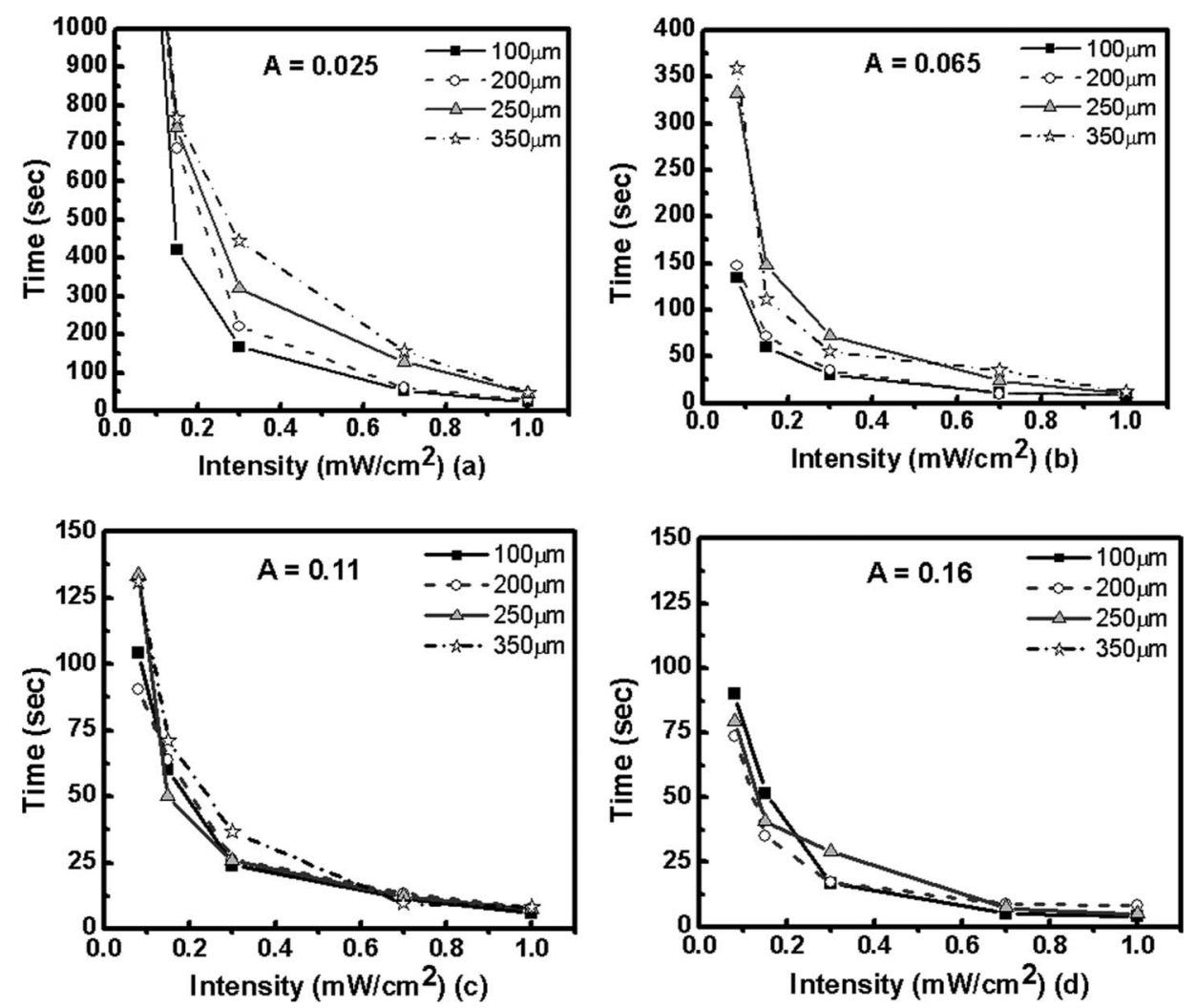

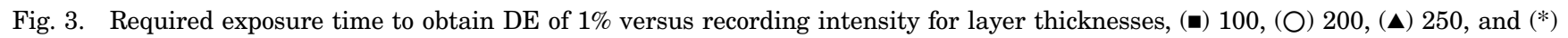
$350 \mu \mathrm{m}$ and absorbances $(0.025,0.065,0.11,0.16)$.
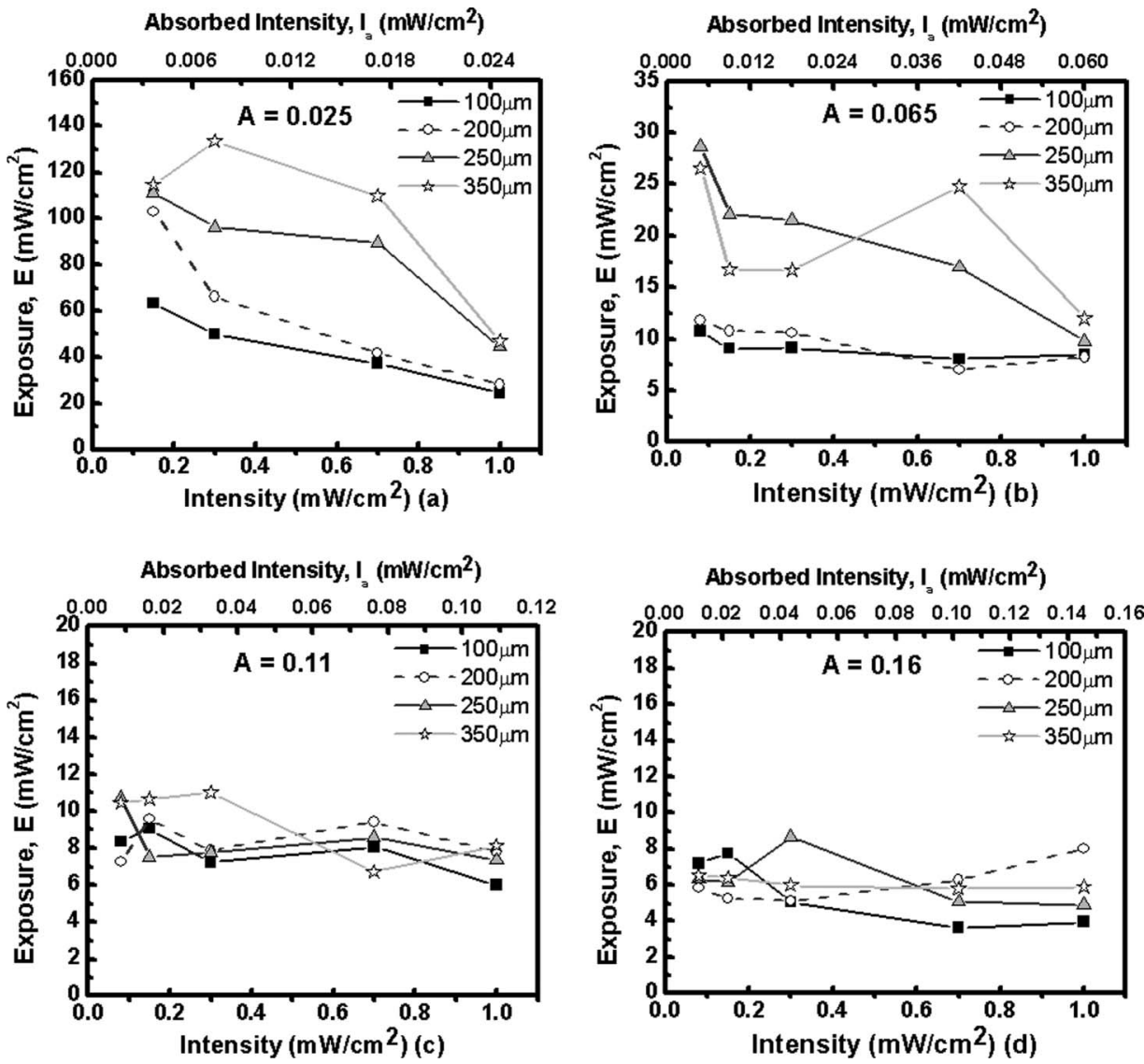

Fig. 4. Exposure for achieving $1 \% \mathrm{DE}$ versus Intensity for different layer thicknesses, (•) 100, (O) $200,(\mathbf{\Delta}) 250$, and (*) $350 \mu \mathrm{m}$ and absorbances $(0.025,0.065,0.11$, and 0.16$)$. The top axis of each of these graphs represents the absorbed intensity, $I_{a}(x)=I(x) \times\left(1-e^{-A}\right)$. 


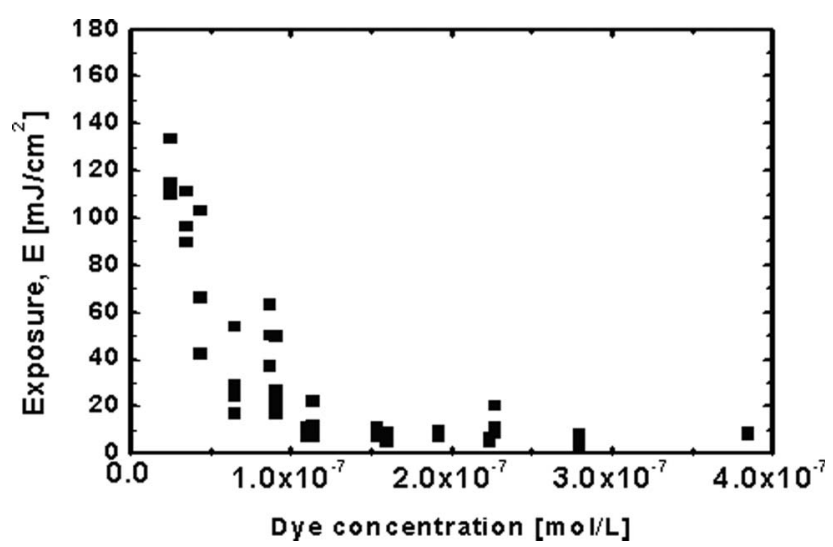

Fig. 5. Exposure needed to obtain $1 \% \mathrm{DE}$ as a function of dye concentration.

needed for overcoming the quenching by production of more free radicals. For higher absorbance, the rate of production of free radicals is much higher (because of the higher number of dye molecules) and the inhibition period is shorter. As a result of a higher number of free radicals produced, the thickness dependence of inhibition effect on photopolymerization cannot be observed.

Figure $\underline{4}$ presents the exposure required for $1 \% \mathrm{DE}$ plotted against intensity, in other words, the total number of photons required for $1 \% \mathrm{DE}$ versus their rate of delivery. The results are grouped by absorbance. As expected, in high absorbance [Fig. 4(d)] the exposure required for $1 \% \mathrm{DE}$ is independent of
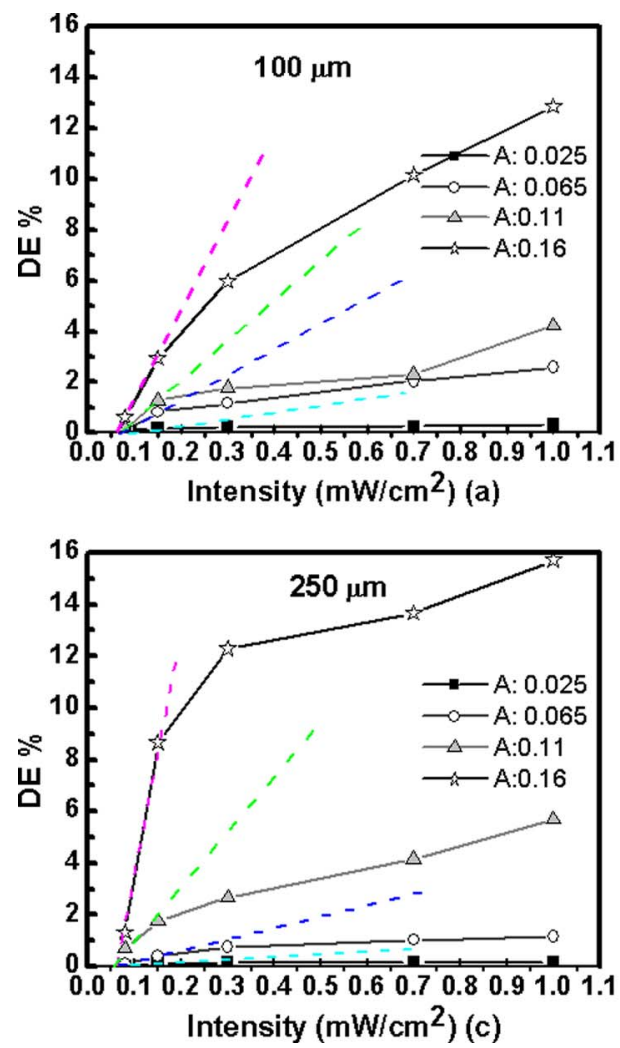

intensity. However, at low absorbance [Fig. 4(a)] the required exposure decreases with intensity. It is also seen that the required exposure is lower for thinner layers, which means that the recording process is more efficient in thin layers at low absorbances. This can be explained by the spatial concentration of photo-generated radicals [29,30] whose mutual proximity is required for cross-linking, which is essential for optimal grating growth. This suggests a threshold concentration of radicals and, therefore, of dye for the efficient formation of stable gratings. Below this threshold, radicals may fail to cross-link and become lost by diffusion from bright to dark fringe regions, thus not contributing to the refractive index modulation. In this regime of recording, higher exposure is necessary to obtain $1 \% \mathrm{DE}$. Another possible reason is that the thick layers might have large amount of oxygen molecules present inside the volume, therefore, longer time is necessary for overcoming the quenching by production of more free radicals.

To investigate the threshold dye concentration, the exposure, required to obtain $1 \% \mathrm{DE}$, as a function of dye concentration is plotted and shown in Fig. 5. Each data point was obtained from the data in Fig. 4 using the molar absorptivity of Erythrosin B solution $\left(2.86 \times 10^{7} \mathrm{l} / \mathrm{mol} / \mathrm{cm}\right)$ at $514.5 \mathrm{~nm}$. From Fig. 5, we obtain a critical dye concentration of approximately $1.5 \times 10^{-7} \mathrm{~mol} / \mathrm{L}$ above which the sensitivity does not increase. Above this concentration, the required exposure energy is $8 \mathrm{~mJ} / \mathrm{cm}^{2}$. This is
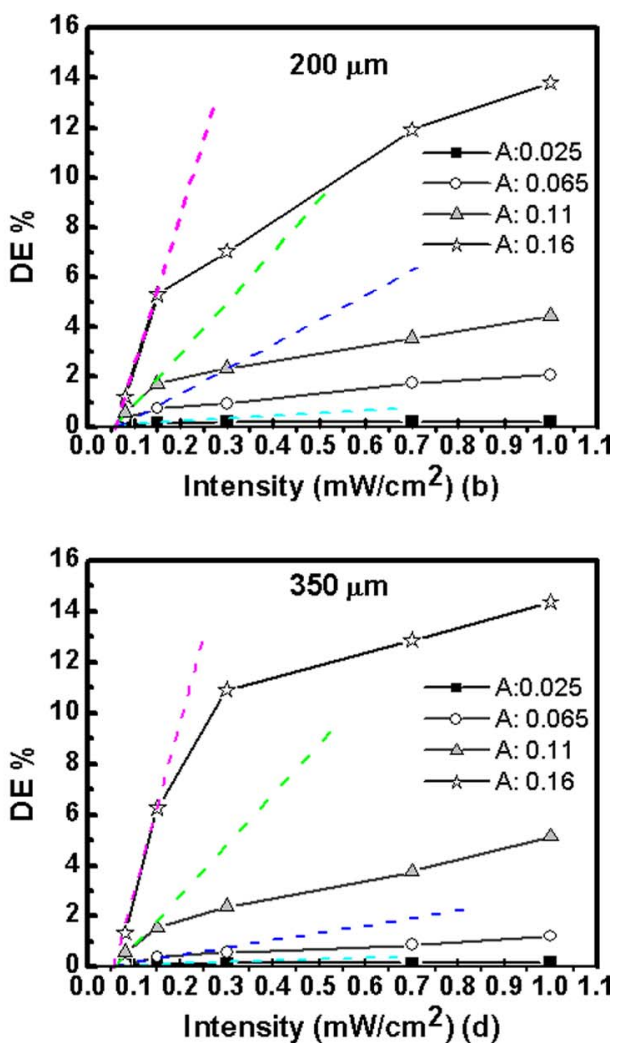

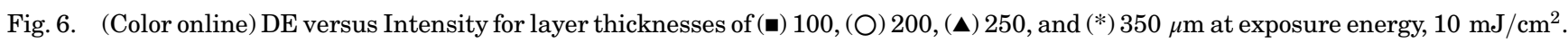




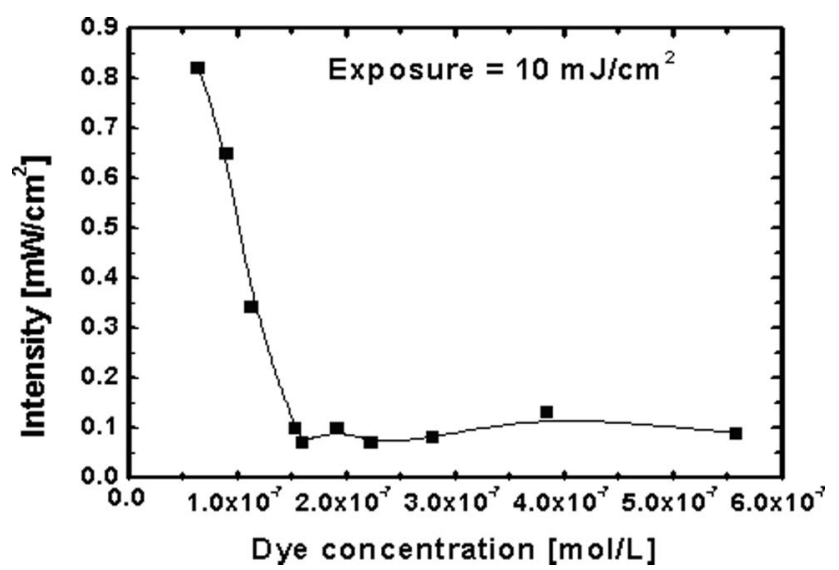

Fig. 7. Dependence of the intensity required for obtaining $1 \% \mathrm{DE}$ on the dye concentration.

the minimum exposure energy required to obtain $1 \%$ $\mathrm{DE}$ regardless of an increase in dye concentration.

\section{Determination of Threshold Intensity $\left(I_{\text {th }}\right)$}

Figure 6 shows the relationship between the DE and the intensity for various layer thicknesses and absorbances at exposure energy of $10 \mathrm{~mJ} / \mathrm{cm}^{2}$. To study the recording process at the beginning of the $\mathrm{DE}$ growth curve, the exposure was selected to ensure that a good comparison was made among all graphs for all absorbances. In Fig. 6, the values of DE were found from the real-time $\overline{\mathrm{DE}}$ measurement graphs (Fig. 2) for each thickness and absorbance at $10 \mathrm{~mJ} / \mathrm{cm}^{2}$. At absorbance $A=0.025$, the DE was $<0.5 \%$ for all thicknesses and increased very slowly with intensity, which is not of practical use for holographic data storage applications. The DE increases with increasing absorbance and intensity. For example, at low absorbance layers $(0.025,0.065)$ the DEs are always considerably lower than the high absorbance $(0.11,0.16)$ layers for all studied layer thickness and intensities.

From Fig. 6 , it is also seen that the slope of the DE curve increases as the absorbance increases. The threshold intensity at a particular absorbance can be determined from the intercept of the $\mathrm{DE}$ curve on the intensity axis where the DE becomes zero. The initial slope of each DE curve was fitted by a linear function and extrapolated to $\mathrm{DE}=0$. It was estimated that the threshold intensity below which no grating was formed was $50 \mu \mathrm{W} / \mathrm{cm}^{2}$. We are aware of the fact that, at low absorbance, the slopes of the DE curves are not well defined and there might be uncertainty in determining the threshold intensity. To obtain a more precise value for threshold intensity using progressively lower exposure intensity and lower dye concentrations of photoactive components is in progress.

These results are of particular interest for the use of a twisted-nematic spatial light modulator (LC2002, HoloEye) and associated polarizing components, as a phase-only modulator [31] in holographic data storage systems because of the low throughput of light in such an optical system. High absorbance layers are not used for recording purposes, mainly due to the creation of noise gratings and scattering losses [11].

Figure 7 shows the recording intensity required to achieve $1 \overline{\%} \mathrm{DE}$ as a function of dye concentration. For dye concentrations lower than $1.5 \times 10^{-7} \mathrm{~mol} / \mathrm{L}$, a strong dependence of recording intensity on the dye concentration was observed. The recording intensity is almost independent of dye concentration above a certain value. It was found that the threshold intensity value for $1 \% \mathrm{DE}$ was $0.09 \mathrm{~mW} / \mathrm{cm}^{2}$ for dye concentrations above $1.5 \times 10^{-7} \mathrm{~mol} / \mathrm{L}$, whereas below this concentration the threshold intensity increases with decreasing dye concentration.

\section{Conclusion}

In conclusion, we have studied the influence of the layer thickness and dye concentration on the holographic recording properties of thick photopolymer layers in the regime of low recording intensity and low dye concentration. In this regime, the rate of generation of free radicals is low and it was observed that the density of the generated free radicals is crucial for effective cross-linking of the created polymer chains and the formation of a hologram. It was estimated that the total threshold intensity below which no hologram can be recorded in the Erythrosin B sensitized layers, characterized by absorbance less than 0.16 , was $50 \mu \mathrm{W} / \mathrm{cm}^{2}$. The real-time diffraction efficiency was analyzed in the early stages of recording. It was determined that the minimum intensity required to obtain $1 \%$ diffraction efficiency in these layers was $90 \mu \mathrm{W} / \mathrm{cm}^{2}$ and the minimum required exposure was $8 \mathrm{~mJ} / \mathrm{cm}^{2}$. It was also determined that there is an optimum dye concentration of $1.5 \times$ $10^{-7} \mathrm{~mol} / \mathrm{L}$ for effective recording. Above this concentration, no increase in the sensitivity of the layers was observed.

DIT provided financial support for this project. The authors thank K. Pavani, D. Bade, Q. Cheng, and J. Keogh (DIT) for their useful discussions and technical support.

\section{References}

1. D. H. Close, A. D. Jacobson, J. D. Margerum, R. G. Brault, and F. J. Mcclung, "Hologram recording on photopolymer materials," Appl. Phys. Lett. 14, 159-160 (1969).

2. W. S. Colburn and K. A. Haines, "Volume hologram formation in photopolymer materials," Appl. Opt. 10, 1636-1641 (1971).

3. J. M. Moran and I. P. Kaminow, "Properties of holographic gratings photoinduced in polymethyl methacrylate," Appl. Opt. 12, 1964-1970 (1973).

4. S. Martin, C. A. Feely, and V. Toal, "Holographic recording characteristics of an acrylamide-based photopolymer," Appl. Opt. 36, 5757-5768 (1997).

5. R. Jallapuram, I. Naydenova, S. Martin, R. Howard, V. Toal, S. Frohmann, S. Orlic, and H. J. Eichler, "Acrylamide-based photopolymer for microholographic data storage," Opt. Mater. 28, 1329-1333 (2006).

6. J. R. Lawrence, F. T. O’Neill, and J. T. Sheridan, "Photopolymer holographic recording material," Optik (Jena) 112, 449-463 (2001). 
7. U. S. Rhee, H. J. Caulfield, J. Shamir, C. S. Vikram, and M. M. Mirsalehi, "Characteristics of the Du-Pont photopolymer for angularly multiplexed page-oriented holographic memories," Opt. Eng. 32, 1839-1847 (1993).

8. A. Pu and D. Psaltis, "High-density recording in photopolymer-based holographic three-dimensional disks," Appl. Opt. 35, 2389-2398 (1996).

9. J. E. Boyd, T. J. Trentler, R. K. Wahi, Y. I. Vega-Cantu, and V. L. Colvin, "Effect of film thickness on the performance of photopolymers as holographic recording materials," Appl. Opt. 39, 2353-2358 (2000).

10. M. Ortuno, S. Gallego, C. Garcia, C. Neipp, and I. Pascual, "Holographic characteristics of a $1 \mathrm{~mm}$-thick photopolymer to be used in holographic memories," Appl. Opt. 42, 7008-7012 (2003).

11. M. S. Mahmud, I. Naydenova, N. Pandey, T. Babeva, R. Jallapuram, S. Martin, and V. Toal, "Holographic recording in acrylamide photopolymers-thickness limitations," Appl. Opt. 48, 2642-2648 (2009).

12. M. D. Goodner and C. N. Bowman, "Development of a comprehensive free radical photopolymerization model incorporating heat and mass transfer effects in thick films," Chem. Eng. Sci. 57, 887-900 (2002).

13. M. R. Gleeson, S. Liu, S. O'Duill, and J. T. Sheridan, "Examination of the photoinitiation processes in photopolymer materials," J. Appl. Phys. 104, 064917 (2008).

14. J. V. Kelly, F. T. O’Neill, J. T. Sheridan, C. Neipp, S. Gallego, and M. Ortuno, "Holographic photopolymer materials: nonlocal polymerization-driven diffusion under nonideal kinetic conditions," J. Opt. Soc. Am. B 22, 407-416 (2005).

15. A. Veltri, R. Caputo, C. Umeton, and A. V. Sukhov, "Model for the photoinduced formation of diffraction gratings in liquidcrystalline composite materials," Appl. Phys. Lett. 84, 3492-3494 (2004).

16. M. D. Goodner, and C. N. Bowman, "Development of a comprehensive free radical photo-polymerization model incorporating heat and mass transfer effects in thick films," Chem. Eng. Sci. 57, 887-900 (2002).

17. G. Odian, ed. Principles of Polymerization (McGraw-Hill, 1970), Chap. 3.

18. C. Croutxé-Barghorn and D. J. Lougnot, "Use of selfprocessing dry photopolymers for the generation of relief optical elements: a photochemical study," Pure Appl. Opt. 5, 811-825 (1996).
19. J. H. Kwon, H. C. Hwang, and K. C. Woo, "Analysis of temporal behavior of beams diffracted by volume gratings formed in photopolymers," J. Opt. Soc. Am. B 16, 1651-1657 (1999).

20. J. R. Lawrence, F. T. O'Neill, and J. T. Sheridan, "Adjusted intensity nonlocal diffusion model of photopolymer grating formation," J. Opt. Soc. Am. B 19, 621-629 (2002).

21. I. Naydenova, R. Jallapuram, R. Howard, S. Martin, and V. Toal, "Investigation of the diffusion processes in a selfprocessing acrylamide-based photopolymer system," Appl. Opt. 43, 2900-2905 (2004).

22. G. Zhao and P. Mourolis, "Diffusion model of hologram formation in dry photopolymer materials," J. Mod. Opt. 41, 19291939 (1994).

23. V. Moreau, Y. Renotte, and Y. Lion, "Characterization of DuPont photopolymer: determination of kinetic parameters in a diffusion model," Appl. Opt. 41, 3427-3435 (2002).

24. V. Colvin, R. Larson, A. Harris, and M. Schilling, "Quantitative model of volume hologram formation in photopolymers," J. Appl. Phys. 81, 5913-5923 (1997).

25. S. Piazzolla and B. Jenkins, "First harmonic diffusion model for holographic grating formation in photopolymers," J. Opt. Soc. Am. B 17, 1147-1157 (2000).

26. J. Frejlich, L. Cescato, and G. F. Mendes, "Analysis of an active stabilization system for a holographic setup," Appl. Opt. 27, 1967-1976 (1988).

27. L. De Sio, R. Caputo, A. De Luca, A. Veltri, C. Umeton, and A. V. Sukhov, "In situ optical control and stabilization of the curing process of holographic gratings with a nematic film-polymerslice sequence structure," Appl. Opt. 45, 3721-3727 (2006).

28. H. Kogelnik, "Coupled wave theory for thick hologram gratings," Bell Syst. Tech. J. 48, 2909-2947 (1969).

29. T. Babeva, I. Naydenova, D. Mackey, S. Martin, and V. Toal, "Two-way diffusion model for short-exposure holographic grating formation in acrylamide based photopolymer," J. Opt. Soc. Am. B 27, 197-203 (2010).

30. S. Martin, I. Naydenova, R. Jallapuram, R. Howard, and V. Toal, "Two-way diffusion model for the recording mechanism in a self-developing dry acrylamide photopolymer," Proc. SPIE 6252, 625205 (2006).

31. M. S. Mahmud, I. Naydenova, and V. Toal, "Implementation of phase-only modulation utilizing a twisted nematic liquid crystal spatial light modulator," J. Opt. A Pure Appl. Opt. 10, 085007 (2008). 